\title{
Modeling of Magnetic Near-Field Radiated by Electronic Devices Disturbed by Transient Signals with Complex Form
}

\author{
Yang Liu, Blaise Ravelo \& Priscilla Fernandez-Lopez \\ IRSEEM (Research Institute on Electronic and Embedded Systems), EA 4353 \\ The graduate School of Engineering ESIGELEC \\ Av. Galilée, BP 10024, 76801 Saint Etienne du Rouvray Cedex, France \\ Tel: 33-232-915-971 \\ E-mail: yang.liu@esigelec.fr; blaise.ravelo@esigelec.fr; priscila.fernandez-lopez@esigelec.fr
}

\author{
Received: November 7, 2011 Accepted: November 21, $2011 \quad$ Published: February 1, 2012 \\ doi:10.5539/apr.v4n1p3 \\ URL: http://dx.doi.org/10.5539/apr.v4n1p3
}

\begin{abstract}
For the safety and reliability of modern hybrid electronic systems in function of the increase of complexity and density integration, relevant modeling methods of near-field (NF) radiation are necessary. This article develops a time-frequency modeling method of electromagnetic (EM) NF emitted by electronic devices excited by transient pulse current. The modeling method is originally flexible to fast switching disturbances propagating in the mixed-systems. The model is based-on the ultra wide band (UWB) model of EM NF maps using a set of elementary EM dipoles. An innovative algorithm for generating a simple reduced model is established. Then, by considering the convolution between the signals exciting the circuit and the UWB model introduced, transient radiation models are realized. The method developed was validated with the magnetic NF radiated at some mm above the microstrip planar DUT. The UWB model effectiveness was verified in RF baseband from DC to 100 MHz. Then, NF map time-dependent model emitted by the circuit excited by a microwave signal modulating 0.9 $\mathrm{GHz}$ carrier with $0.6 \mathrm{GHz}-1.2 \mathrm{GHz}$ frequency band is also validated. As expected, good agreements between simulations, measurements and the models investigated are observed for any form of excitation current.
\end{abstract}

Keywords: Magnetic radiation, Near-field (NF), Time-frequency method, EMC application, Transient model

\section{Introduction}

Facing to the complexity of modern electronic architectures and systems, the issues related to the unintentional electromagnetic compatibility interference (EMI) becomes one of critical embedded equipment malfunction sources (Vye, D., 2011) (Yang, T., et al., 2010). In this optic, deeming with functional features of automotive vehicles, several electronic components and printed circuit board (PCB) can be seriously unsafe (Archambeault, B., et al., 2010) (Kopp, M., 2011) (Liu, K., 2011) (T, Hubing., 2011). In other hand, with the need of public demands, our planet is also increasingly connected through electromagnetic (EM) communications (Tröscher, M., 2011). Electromagnetic compatibility (EMC) of various telematics element internal to automobiles due to mobile hotspots and as the electronic content (wireless links, multimedia devices, electronic control modules, electric hybrid drives, etc.), as well as compatibility to the environment that they operate in, are becoming more challenging to designers in automotive industries (Wiles, M., 2003) (Shin, J., 2011) (Liu, K., 2002). To meet the different international standards requirement (automotive directive 72/245/EEC, ISO 11451-2, IEC 61000-4-21:2011, SAE J1113, CISPR 25) (Shi, J., et al., 1989), testing technique at both full vehicle and component levels serves as one of the critical links to the overall integrity and functional verification of automotive vehicle designs (Shin, J., 2011).

To overcome this technical problem, the radiating and conducting EMC characterization cannot be neglected during the design process. So, characterization techniques are proposed in (Weng, H., et al., 2011) (Baudry, D., et al., 2007) (Fan, H. \& Schlagenhaufer, F., 2007a) (Weng, H., et al., 2005) (De Daran, F., et al., 2003) (Labussiere-Dorgan, C., et al., 2008) (Taaghol, A. \& Sarkar, T. K., 1996) (Fan, H. \& Schlagenhaufer, F., 2007b) (Alvarez López, Y., et al., 2009) for the prediction of the undesired near-field (NF) produced by the analog, digital and mixed circuits. Because of the probe calibration difficulty as well as the time duration and complexity 
of computing methods for the 3D structures, monochromatic radiation NF modeling methods were introduced (Regué, J. R., et al., 2005) (Vives-Gilabert, Y., et al., 2007a, 2007b, 2009). The NF emission model can be used to predict both magnetic and electric NF radiated by electronic devices as stated in (Fernández-López, P., et al., 2009,2010 ) in order to predict the reliability and safety of equipments susceptible to be disturbed by EM coupling. The latter cited methods (Vives-Gilabert, Y., et al., 2007a, 2007b, 2009) (Fernández-López, P., et al., 2009, 2010) are based on the set of elementary methods as introduced in (Balanis, C. A., 2005) (Schantz, H. G., 2001) (Jun-Hong, W., et al., 1997).

Moreover, a wide range and flexible NF emission modeling method becomes an essential phase for the electronic design and validation engineers. To cope with the operating speed augmentation of current systems, the current and voltage communications in the electrical/electronic devices such as diodes, MOSFETs and also the amplifiers can create critical unintentional transient disturbances which can generate the transient EM radiations (Jauregui, R., et al., 2010) (Scriven, I. \& Lewis, A., 2010). The propagation of these undesired radiations must be mastered by the designers and manufacturers in order to forecast their influences on the neighboring circuits. In this case, only the monochromatic single frequency model is not at all sufficient for the analysis of fast switching which can cause transient phenomena. That is why the radiating EM NF model in time-domain is necessary. To investigate analytically these types of emissions, the time-domain propagation approach based-on the elementary dipoles radiation is necessary (Song, J. \& Chen, K.-M., 1993) (Lakhtakiaa, A., et al., 1987) (Cicchetti, R., 1991). Till now, few relevant models were published in the literature for the fast transient NF emission in time-domain (Shlivinski, A., et al. 1997) (Hansen, T. B. \& Yaghjian, A. D., 1994) (Winter, W. \& Herbrig, M., 2009). So, a scanning method was proposed in (Ordas, T., et al. 2009) but the treatment of raw data remains inaccurate due to the imperfection of the probe calibration technique considered. For this reason, it was recently promised with semi-analytical computation method that one can extract time-domain EM NF map from the frequency results (Ravelo, B. \& Liu, Y., in press) (Ravelo, B., et al., 2011b). As extension of this method with more realistic use cases, in this article, we transpose this time-frequency method to the modeling of magnetic- or H- NF introduced in (Vives-Gilabert, Y., et al., 2007a, 2007b, 2009) for investigating the transient NF propagation radiated by electronic devices in baseband and RF frequencies. As argued previously, the time-dependent model is determined from the broadband frequency model of the field maps. Then, the model is convoluted with the complex wave transient excitation signal susceptible to disturb the electrical/electronic devices understudy in order to generate the time-domain NF cartographies.

To get a better insight about the feasibility of the modeling method understudy, this article is organized in four main sections. Section II focus is on the methodology of the broadband modeling of electronic devices NF radiation by considering an optimal set of elementary electric dipoles. Section III explains how the interaction between the excitation signal and the broadband model is realized to characterize time-dependent mapping NF field. Then, validation results of the time-frequency model investigated with a concrete circuit is presented in Section IV. This practical verification will be made with the design and test of planar microstrip device excited by UWB signals. Lastly, Section V draws the conclusion.

\section{Methodology of the Broadband Modeling Method Proposed for the Magnetic Nf Radiated by Electronic Devices}

The model investigated in this article is defined from the given map data of the scanned magnetic NF as introduced in (Vives-Gilabert, Y., et al., 2007a, 2007b, 2009) combined with the time-frequency computation technique proposed in (Ravelo, B. \& Liu, Y., in press). For the sake of mathematical expression simplification, we suppose that the scan magnetic field is represented in the $X Y$-plane with $n_{x} \mathrm{x} n_{y}$ number of points. By the inverse direct calculation, we can determine the adequate configuration of the set of $n_{d}$-dipoles generating the same behaviour of magnetic NF radiation. Before the exploration of the time-domain modeling method understudy, let us first examine the calculation process of the dipole parameters knowing the magnetic field data.

\subsection{Recall on the Magnetic NF Modeling Method by Using a Set of Electric Dipoles}

We assume that the complex values of transversal components $H_{x}$ and $H_{y}$ of the NF magnetic field map were represented in $X Y$-plane positioned at the height $z_{0}$ above the radiating source. This single-frequency monochromatic NF wave model was established in (Vives-Gilabert, Y., et al., 2007a, 2007b, 2009) that:

$$
\begin{aligned}
& {\left[H_{x}\right]=\left[\alpha_{x}\right] \cdot\left[I_{0} \sin (\theta)\right]} \\
& {\left[H_{y}\right]=\left[\alpha_{y}\right] \cdot\left[I_{0} \cos (\theta)\right],}
\end{aligned}
$$

with:

- $[\alpha x]$ and $[\alpha y]$ are two matrices whose elements depend on the space coordinates and the centers of dipoles, 
- $\theta$ is the orientation angles of dipoles,

- $\quad$ and $\mathrm{I} 0$ is the intensity of the currents which excite the elementary dipoles.

The first step of the modeling process consists in the determination of dipole orientations in the $X Y$-plane by using the following inverse matrix expression:

$$
\begin{aligned}
& {\left[\alpha_{x}\right]^{-1}\left[H_{x}\right]=\left[I_{0} \sin (\theta)\right]=\left[A_{x}\right]} \\
& {\left[\alpha_{y}\right]^{-1}\left[H_{y}\right]=\left[I_{0} \cos (\theta)\right]=\left[A_{y}\right],}
\end{aligned}
$$

with the orientation angles are given by:

$$
\theta_{k}=\arctan \left(\frac{A_{x, k}}{A_{y, k}}\right)_{k=\left\{1 \ldots n_{d}\right\}} .
$$

Then, the amplitudes of each harmonic current flowing through the dipoles are calculated with the matrix multiplication:

$$
\left[I_{0}\right]=\left[\begin{array}{c}
\alpha_{x} \sin \theta \\
\alpha_{y} \cos \theta
\end{array}\right]^{-1}\left[\begin{array}{l}
H_{x} \\
H_{y}
\end{array}\right],
$$

In this case, we point out that the dipoles synthesized must be placed in the $X Y$-plane positioned at $z_{0}$ below the considered test plane which can be supposed as the measurement plane. As argued in (Vives-Gilabert, Y., et al., 2007a), only the horizontal components of the magnetic NF are sufficient for the determination of total field along the mapping plane considered because the vertical component $H_{z}$ can be generated automatically by the set of dipoles synthesized from (2) and (3).

\subsection{Determination of the Reduced Broadband Model of the Magnetic NF}

As illustrated in Fig. 1, we suppose that the $n_{f}$ maps of the magnetic NF is given in the broad- and base-band frequencies delimited from $f_{\min }=f_{1}$ to $f_{\max }=f_{n f}$. Meanwhile the step frequency is $\Delta f=\left(f_{\max }-f_{\min }\right) / n_{f}$.

By considering the relative error between maps with indexes $n_{k 1}$ and $n_{k 2}$ :

$$
\varepsilon_{n_{k 2}}=\sum_{i} \frac{\left|H_{n k 2}\left(M_{i}\right)-H_{n k 1}\left(M_{i}\right)\right|^{2}}{\sum_{j}\left|H_{n k 1}\left(M_{j}\right)\right|^{2}},
$$

we can reduce the number of NF maps from $n_{f}$ to $r n_{f}$ with its initial label by assuming as the maps presenting relative errors $\varepsilon_{n_{k 2}}<0.05$ as identical maps. With the optimal discrete frequencies $\left\{f_{1} \ldots f_{r n f}\right\}$, we apply the inverse method presented in the previous subsection.

Therefore, a reduced model of broadband model is realized. This reduced model contains dipoles characterized by current amplitudes $\left.\left[I_{0}\right]_{k_{f}=\left\{1 \ldots r n_{f}\right.}\right\}$ and orientation angle matrix $[\theta]_{k_{f}=\left\{1 \ldots r n_{f}\right\}}$.

With the inverse process illustrated in Fig. 2, we can generate the total frequency data from $f_{1}$ to $f_{n f}$ as given initially.

In the next section, the transposition of this broadband frequency-dependent model into time-domain data will be investigated based-on the linear time-independent (LTI) system theory.

\section{Extraction of the Time-Domain Model Form the Uwb Frequency-Dependent Mapping Data}

The present section explains how the transient excitation signal time-parameters should be chosen before the implementation of the interaction algorithm with the frequency-dependent model established previously. Afterward, the development of the routine process indicating the proposed computation method algorithm is elaborated and validated with an example of use case electronic magnetic NF emission.

3.1 Frequency-Dependent Coefficients Extraction in Function of the Ultra-Short Duration Transient Signal Considered

Let us denote $i(t)$ the input signal assumed as the transient disturbing excitation of the structure under test. The sampled data corresponding to this disturbing signal is supposed discretized from the starting time $t_{\min }$ to the stop 
time $t_{\max }$ with time step equal to $\Delta t$. In this case, the number $n$ of time-domain sample data is equal to:

$$
n=\operatorname{int}\left(\frac{t_{\max }-t_{\min }}{\Delta t}\right) \text {. }
$$

The term $\operatorname{int}(\alpha)$ expresses the lowest integer number greater than the real $\alpha$. Accordingly, the equivalent frequency-dependent spectrum of $i(t)$ can be determined via the fast Fourier transform $(f f t)$ which allows to get the complex current harmonic $\underline{I}(f)=f f t[i(t)]$ as depicted in Fig. 3 in function of sampled frequency.

The frequency-dependent of the discrete signal spectrum complex coefficients is denoted $\underline{c}_{k}=\underline{I}(k \cdot \Delta f)$ at each frequency $f_{k}=k \cdot \Delta f$ for $k=\{1 \ldots n\}$ having step-frequency given by:

$$
\Delta f=\frac{1}{t_{\max }-t_{\min }},
$$

We point out that in baseband application, this method requires a frequency range $\left[f_{\min }, f_{\max }\right]$ whose the lowest frequency value $f_{\min }$ of $\underline{I}(f)$-data is equal to the step frequency $\Delta f$. It means that we can extrapolate the signal spectrum or the excitation signal steady-state component. This does not change the calculation results because according to the signal processing theory, the DC-component of transient pulse signals with ultra-short time duration at very low frequencies is always negligible. The upper frequency limit $f_{\max }$ should correspond to the frequency bandwidth containing most of the considered excitation signal spectrum energy (Ravelo, B. \& Liu, Yang., in press) (Ravelo, B., 2010) (Ravelo, B., et al., 2011a).

\subsection{Extraction of Time-Dependent Magnetic Field from Broadband Frequency-Data}

As aforementioned, the present study is focused on the magnetic NF modeling. The routine process of the time-frequency computation-method proposed here is consisted of two different steps consecutive. The first step consists in the time-dependent characterization of the excitation signal $i(t)$. This latter must be sampled in the adequate time-interval range from $t_{\min }$ to $t_{\max }$ with time-step $\Delta t$. In the following step, the complex frequency-coefficients $\underline{c}_{k}$ representing the spectrum of $i(t)$ should be extracted with the fft-operation as explained in previous subsection. The following step is the conversion of the frequency-dependent magnetic NF expressed by $\underline{H}\left(x, y, z_{0}, f\right)$ at the point $M\left(x, y, z_{0}\right)$ into a time-dependent data denoted by $H\left(x, y, z_{0}, t\right)$ toward the ifft-operation. We underline that each point where the field is calculated must belong in the $X$-Y plane positioned at $z=z_{0}$. In this case, the frequency range of $\underline{H}(f)=\underline{H}\left(x, y, z_{0}, f\right)$ must be well-synchronized with the frequency range of the excitation signal frequency-coefficients $\underline{c}_{k}$. Under this condition, the desired time-dependent data $H(t)=H\left(x, y, z_{0}, t\right)$ corresponding to the specific excitation signal $i(t)$ can be calculated through the inverse fast Fourier transform of the results obtained after the convolution between the source considered $i(t)$ and frequency data $\underline{H}(f)$ as indicated in Fig. 4.

\subsection{Methodology of the Time-Dependent Model Computation from the Reduced Model Established}

In nutshell, the time-frequency model method of the EM NF radiated by electronic devices proposed in this article is performed in four main steps. The model proposed necessitates only the transversal components $\left(H_{x}\right.$ and $H_{y}$ ) of the radiating device.

- Step 1 is the determination of the reduced map series $H_{r m}(f)$ of the frequency-dependent field data.

- Step 2 is the calculation of the elementary dipole parameters.

- Step 3 is the calculation of the field maps $H_{m}(f)$ required in accordance with the time-dependent $\left(t_{\min }, t_{\max }\right.$ and $n_{t}$ ) of the excitation signal $i(t)$ under consideration. It is noteworthy that in this step, the z-component of the field can be calculated by using the dipole radiation defined in (Vives-Gilabert, Y., et al., 2007b) (Balanis, C. A., 2005).

- The last step is the determination of the time-dependent field maps through the convolution of the excitation signal and the field radiated by the dipoles model.

Fig. 5 represents the working principle highlighting the different operations successive to be fulfilled for the achievement of the model computation-method. After the implementation of this computational algorithm into Matlab program, we realize the results from the model proposed discussed in the next section.

\section{Validation Results}

To demonstrate the relevance of the modeling method presented previously, a prototype of planar electronic devices having arbitrary shape was designed, simulated, fabricated and measured. The magnetic fields radiated by the device under test (DUT) were computed through simulations performed with 3D EM standard simulation 
tool CST MWS both in frequency- and time-domains. In addition, measurements were also carried out in broadband frequency. Two types of models are validated in this article; the first one corresponds to the baseband RF radiation. This use case can represent the EMI induced by the inductive load switching, wiring interface, ignition interruption or turnoff, voltage sag during engine starting, and the alternator load dump transient (Vye, D., 2011). The other one corresponds to the modulated signals which can be assumed as radiations from the type of GSM D-net and different land mobile radio transmitters.

\subsection{Design of the Planar Microstrip DUT}

As a concrete demonstrator, an electronic circuit implemented in planar microstrip technology with dimensions $90 \mathrm{~mm} \times 110 \mathrm{~mm}$ was designed. Its layout top view representing its geometrical form is provided in Fig. 6 . This device was printed on the FR4-epoxy substrate having relativity permittivity $\varepsilon_{r}=4.4$, thickness $h=1.6 \mathrm{~mm}$ and etched with Cu-metal having thickness $t=35 \mu \mathrm{m}$. The cut cross section of this circuit is depicted in Fig. 7 .

As said previously, this structure was simulated in baseband frequency from DC to $100 \mathrm{MHz}$. The subsequent radiation maps are assumed as low frequency (LF) maps.

Then, the circuit understudy is simulated by considering a microwave signal modulating an ultra-short Gaussian pulse current. It enables to generate the radiation maps corresponding to the high frequency (HF) maps. The transient radiation will be calculated by using the method described in Fig. 5 and the results obtained are compared with CST simulations and experimental field data.

\subsection{LF Validation Results}

In this case, the circuit prototype shown in Fig. 6 is simulated via the frequency solver of CST MWS. The simulation was carried out from DC to $100 \mathrm{MHz}$ with 101 sampling points. Afterwards, we applied to the frequency-dependent data obtained the reduction method introduced in subsection II.B. Then, the reduced broadband model of dipoles set was determined for the frequency band considered. Then, the modeled field map at any frequency in this frequency band can be computed by using the elementary dipole radiation defined in (Balanis, C. A., 2005). Comparisons were made with the CST simulation results.

To demonstrate the effectiveness of the method, we choose arbitrarily radiation magnetic field maps scanned at in the horizontal plane placed at $\mathrm{z} 0=7 \mathrm{~mm}$ above the DUT metallic plane and at the three frequencies $\mathrm{f}=\{20$ $\mathrm{MHz}, 60 \mathrm{MHz}, 100 \mathrm{MHz}$. As shown in Figs. 8, one can figure out that a very good agreement between the model developed and the CST simulation has been found. We can see that in all the case, the field value and distribution is almost same, although there is a little difference on the map bounds where the magnetic field values are generally negligible.

\subsection{Microwave HF Validation Results}

In this part, the DUT depicted in Fig. 6 is simulated and measured in microwave HF band. The frequency range of interest was set from $0.6 \mathrm{GHz}$ to $1.2 \mathrm{GHz}$ with 201 sampling points. In this case, it is important to note that the reduced broadband model was determined from the measured experimental data by using the circular loop probe with $6 \mathrm{~mm}$ diameter pictured in Fig. 9. The measurement was carried out with the IRSEEM NF test bench presented in Fig. 10 and treated with the calibration method proposed in (Vives-Gilabert, Y., et al., 2007a, 2007b, 2009) (Fernández-López, P., et al., 2009, 2010) but in this case, applied to wide band frequency range.

Then, comparisons were made between the results obtained from measurements, simulations and the model proposed. Figs. 11 represent the magnetic field maps scanned at $z_{0}=7 \mathrm{~mm}$ above the DUT and radiated at the arbitrary chosen frequency $f=\{0.6 \mathrm{GHz}, 0.9 \mathrm{GHz}, 1.2 \mathrm{GHz}\}$. So, we can see that the results obtained present a good correlation in terms of the behaviours. The apparent difference between the field values is mainly due to the measurement inaccuracies related to the probe position and the influence of the grid mesh configuration during the simulations. We emphasize that the computations were performed with a 32-bit-PC which presents a considerable limit of physical and virtual memory. For the sake of the numerical accuracy, the spatial resolution of the scanned data was reduced to about $5 \mathrm{~mm}$.

\subsection{Time-Domain Validation Results}

In this subsection, we focus on the comparison between the time-domain results computed from the modeling method described in Fig. 4 and those from the CST MWS transient solver. To do this, the DUT was excited by the modulated ultra-short current displayed in Fig. 12. It acts as a Gaussian wave with half-width at half maximal-height of about $1.5 \mathrm{~ns}$ modulating a $0.9 \mathrm{GHz}$ sine carrier. We can see that the signal time duration is equal to $t_{\max }=12 \mathrm{~ns}$ and sampled with $n_{t}=201$ points. As can be seen in Fig. 12, the corresponding spectrum is situated from about $0.6 \mathrm{GHz}$ to $1.2 \mathrm{GHz}$. To establish the reduced model with the set of dipoles, we considered 
51 sampled frequency points instead of 201 points. This transient signal was convoluted with the frequency data from the reduced model established from the flow chart presented in Fig. 5 in order to generate the time-domain NF maps.

Therefore, we obtain the magnetic NF maps displayed in Figs. 13 at the arbitrarily chosen instant time $t=7 \mathrm{~ns}$. Once again, we observe here a good correlation between the $H_{x}$ and $H_{y}$ maps. These results confirm the feasibility of the time-frequency modeling method investigated.

However, there are still some differences which are mainly due to the numerical inaccuracies. These results can be enhanced by using powerful computers capable to perform calculations with high space-time resolutions. The $\mathrm{PC}$ we used for the computation and simulation is equipped a single-core processor XEON $3.4 \mathrm{GHz}$ and $4 \mathrm{~GB}$ physical memory with 32-bits Windows XP. The size of data matrix is necessarily limited by the physical and virtual memory. Accordingly, the spatial step has to be reduced to $4 \mathrm{~mm}$ to ensure the computing process. We emphasize that the present modeling method were run in total computation time of about 5 minutes by using a Matlab program. With the same configuration, by using the default simulation setting ( the number of time steps is 1001), the CST simulation costs usually about 2 hours in order to obtain 102 cartographies of 3D fields in time-domain.

\section{Conclusion}

Facing the increase of the electrical/electronic system density in confined space of embedded systems and to guarantee the safety vis-à-vis NF emissions, the design and manufacture engineers need a deep understanding enabling to predict system reliabilities by taking into account the complex current disturbances. Till now, most of NF radiation models were dedicated to the single harmonic excitation. But it is not actually sufficient for investigating most of transient NF radiation use cases.

A time-frequency modeling of NF radiated by electronic circuits for LF and HF applications is developed in this article. The method is based on the broadband modeling of EM NF maps by using a set of elementary dipoles. A routine algorithm allowing to realize a reduced number of field maps is established. From where, the transient NF model was determined via the convolution of the excitation current source and the reduced broadband model established. It is based on the exploitation of the frequency-dependent mapped EM-field data regarding the excitation current operated with fft. To confirm the feasibility of the computation method, a planar electronic device was excited with an ultra-short duration transient pulse signal. It was demonstrated that a very good correlation between the UWB magnetic NF maps radiated by DUT was found both in frequency- and time-domains. We point up that the NF computation method developed in this article presents considerable advantages in terms of:

1) The simplicity of the EM NF map calculation and also the possibility to take into account the ultra-short duration transient excitation. It offers a new treatment process of NF prediction in time domain.

2) It is flexible for large spectrum of LF and HF EMI disturbances modeling which are useful for the hybrid systems with complex forms. The method can be adapted to any form of LF and HF signals.

3) With baseband measured data, we can predict EM NF results in time-domain from frequency-dependant data and vice-versa.

However, the main drawback of the modeling method developed is the limitation in terms of time step parameter which depends mainly on the frequency range of the considered initial frequency-data and the used PC performance.

In the continuation of this work, we plan to apply this method with both magnetic- and electric- NF models in broadband frequency applications and also in time-domain.

\section{Acknowledgement}

These research works have been implemented within the frame of the "Time Domain Electromagnetic Characterisation and Simulation for EMC" (TECS) project which is part-funded by the Haute-Normandie Region and the ERDF via the Franco-British Interreg IVA programme No. 4081.

\section{References}

Alvarez López, Y., Las Heras Andrés, F., Rodríguez Pino, M., \& Sarkar, T. K. (2009). An Improved Super-resolution Source Reconstruction Method. IEEE Trans. Instrum. Meas., Vol. 58, No. 11, pp. 3855-3866.

Archambeault, B., Brench, C., \& Connor, S. (2010). Review of Printed-Circuit-Board Level EMI/EMC Issues and Tools. IEEE Trans. EMC, Vol. 52, No. 2, pp. 455-461. 
Balanis, C. A. (2005). Antenna Theory: Analysis and Design (3rd ed.). Wiley, New York, USA.

Baudry, D., Arcambal, C., Louis, A., Mazari, B. and Eudeline, P. (2007). Applications of the Near-Field Techniques in EMC Investigations, IEEE Trans. EMC, Vol. 49, No. 3, pp. 485-493.

Cicchetti, R. (1991). Transient Analysis of Radiated Field from Electric Dipoles and Microstrip Lines, IEEE Trans. Ant. Prop., Vol. 39, No. 7, pp. 910-918.

CISPR 25. Ed 3.0. (2008-03). Vehicles, Boats and Internal Combustion Engines-Radio Disturbance Characteristics - Limits and Methods of Measurement of Radio Disturbance Characteristics for the Protection of Receivers.

de Daran, F., Chollet-Ricard, J., Lafon, F., \& Maurice, O. (2003). Prediction of the Field Radiated at One Meter from Microprocessors from Near EM Field Cartography. Proc. of IEEE Int. Symp. EMC, Istanbul, Turkey, pp. 479-482.

Fan, H., \& Schlagenhaufer, F. (2007). Near-Field-Far Field Conversion Based on Genetic Algorithm for Predicting Radiation from PCBs. Proc. of IEEE Int. Symp. EMC, Honolulu, HI, pp. 1-6.

Fan, H., \& Schlagenhaufer, F. (2007). Investigation of Near Field Data Sampling Approaches for Far Field Radiation Prediction of PCBs by Genetic Algorithm. Proc. of 18th Int. Zurich Symp. EMC, Munich, Germany, pp. 21-24.

Fernández-López, P., Arcambal, C., Baudry, D., Verdeyme, S., \& Mazari, B. (2009). Radiation Modeling and Electromagnetic Simulation of an Active Circuit. Proc. of EMC COMPO 09, Toulouse, France.

Fernández-López, P., Arcambal, C., Baudry, D., Verdeyme, S., \& Mazari, B. (2010). Simple Electromagnetic Modeling Procedure: From Near-Field Measurements to Commercial Electromagnetic Simulation Tool. IEEE Trans. Instrum. Meas., Vol. 59, No. 12, pp. 3111-3120.

Hansen, T. B., \& Yaghjian, A. D. (1994). Planar Near-Field Scanning in Time Domain, Part 2: Sampling Theorems and Computation Schemes, IEEE Tran. Ant. Prop, Vol. 42, No. 9.

IEC 61000-4-21:2011, Ed. 2.0, Electromagnetic compatibility (EMC) - Part 4-21: Testing and Measurement Techniques.

ISO 11452, Components - Vehicle Test Methods for Electrical Disturbances by Narrowband Radiated Electromagnetic Energy.

Jauregui, R., Pous, M., Fernández, M., \& Silva, F. (2010). Transient Perturbation Analysis in Digital Radio, in Proc of IEEE Int. Symp. EMC, Fort Lauderdale, Florida (USA), pp. 263-268.

Jun-Hong, W., Lang, J., \& Shui-Sheng, J. (1997). Optimization of the Dipole Shapes for Maximum Peak Values of the Radiating Pulse, in Proc. of IEEE Tran. Ant. Prop. Society Int. Symp., Montreal, Quebec, Vol. 1, pp. 526-529.

Kopp, M. (2011). Automotive EMI/EMC Simulation, Microwave Journal, Vol. 54, No. 7, pp. 24-32.

Labussiere-Dorgan, C., Bendhia, S., Sicard, E., Tao, J., Quaresma, H. J., Lochot, C., \& Virgnon, B. (2008). Modeling the Electromagnetic Emission of a Microcontroller Using a Single Model, IEEE Trans. EMC, Vol. 50, No. 1, pp. 22-34.

Lakhtakiaa, A., Varadana, V. K., \& Varadana, V. V. (1987). Time-Harmonic and Time-Dependent Radiation by Bifractal Dipole Arrays. Int. J. Electronics, Vol. 63, No. 6, pp. 819-824.

Liu, K. (2011). An Update on Automotive EMC Testing, Microwave Journal, Vol. 54, No. 7, Jul. 2011, pp. 40-46.

Liu, K. (2002). Site Definition and Validation for Automobile Component Test Chambers, Invited Presentation at Society of Automotive Engineers (SAE) Work Group Meeting, Detroit, MI.

Ordas, T., Lisart, M., Sicard, E., Maurine, P., \& Torres, L. (2009). Near-Field Mapping System to Scan in Time Domain the Magnetic Emissions of Integrated Circuits. Proc. of PATMOS' 08: Int. Workshop on Power and Timing Modeling Optimization and Simulation, Ver. 1-11.

Ravelo, B., \& Liu, Y. Extraction of Transient Near-Fields Radiated by Electronic Devices from Frequency Data, in press, to be published in INTECH Book, (chapter under the working title "Fourier Transform / Book 1"), ISBN 979-953-307-537-1, Ed. By S. Salih. 
Ravelo, B. (2010). E-Field Extraction from H-Near-Field in Time-Domain by Using PWS Method. PIER B J., Vol. 25, pp. 171-189.

Ravelo, B., Liu, Y., \& Slama, J. B. H. (2011a). Time-Domain Planar Near-Field/Near-Field Transforms with PWS Method. Eur. Phys. J. Appl. Phys. (EPJAP), Vol. 53, No. 1, 30701-pp. 1-8.

Ravelo, B., Liu, Y., Louis, A., \& Jastrzebski, A. K. (2011b). Study of high-frequency electromagnetic transients radiated by electric dipoles in near-field, IET Microw., Antennas Propag., Vol. 5, No. 6, pp $692-69$.

Regué, J. R., Ribó, M., Gomila, J., Pérez, A., \& Martín, A. (2005). Modeling of Radiating Equipment by Distributed Dipoles Using Metaheuristics Methods, in Proc. of IEEE Int. Symp. EMC, Chicago, IL, pp. 8-12.

SAE J1113, Electromagnetic Compatibility Measurement Procedures and Limits for Vehicle Components.

Schantz, H. G. (2001). Electromagnetic Energy around Hertzian Dipoles, IEEE Tran. Ant. Prop. Magazine, Vol. 43, No. 2, pp. 50-62.

Scriven, I., Lu, J. \& Lewis, A. (2010). Electromagnetic Noise Source Approximation for Finite-Difference Time-Domain Modeling Using Near-Field Scanning and Particle Swarm Optimization, IEEE Tran. EMC, Vol. 52, No. 1.

Shin, J. (2011). Automotive EMC Standards and Testing, Tutorial Workshop Digests on "Introduction to Automotive EMC Testing" at the 2011 APEMC, Jeju, S. Korea.

Shi, J., Cracraft, M. A., Zhang, J., \& DuBroff, R. E. (1989). Using Near-Field Scanning to Predict Radiated Fields, IEEE Ant. Prop. Int. Symp. 1989, San Jose, CA (USA), Vol. 3, pp. 1477-1480.

Shlivinski, A., Heyman, E., \& Kastner, R. (1997). Antenna Characterization in the Time Domain. IEEE Trans. Ant. Prop., Vol. 45, No. 7, pp. 1140-1149.

Song, J., \& Chen, K.-M. (1993). Propagation of EM Pulses Excited by an Electric Dipole in a Conducting Medium, IEEE Tran. Ant. Prop., Vol. 41, No. 10, pp. 1414-1421.

T, Hubing. (2011). Ensuring the Electromagnetic Compatibility of Safety Critical Automotive Systems, Invited Plenary Speaker at the 2011 APEMC, Jeju, South-Korea.

Taaghol, A., \& Sarkar, T. K. (1996). Near-Field to Near/Far-Field Transformation for Arbitrary Near-Field Geometry, Utilizing an Equivalent Magnetic Current, IEEE Trans. EMC, Vol. 38, No. 3, pp. 536-542.

Tröscher, M. (2011). 3D EMC/EMI Simulation of Automotive Multimedia Systems, Microwave Journal, Vol. 54, No. 7, pp. 34-38.

Vives-Gilabert, Y., Arcambal, C., Louis, A., Daran, F., Eudeline, P., \& Mazari, B. (2007). Modeling Magnetic Radiations of Electronic Circuits using Near-Field Scanning Method, IEEE Tran. EMC, Vol. 49, No. 2, pp. 391-400.

Vives-Gilabert, Y., Arcambal, C., Louis, A., Mazari, B., \& Eudeline, P. (2007). Measuring amplitude and phase of radiated electromagnetic near fields, in Proc. of 3rd ICONIC, St. Louis, MO, pp. 27-32.

Vives-Gilabert, Y., Arcambal, C., Louis, A., Eudeline, P., \& Mazari, B. (2009). Modeling Magnetic Emissions Combining Image Processing and an Optimization Algorithm, IEEE Tran. EMC, Vol. 51, No. 4, pp. 909-918.

Vye, D. (2011). EMI by the Dashboard Light, Microwave Journal, Vol. 54, No. 7, pp. 20-23.

Weng, H., Beetner, D. G., \& DuBroff , R. E. (2011). Prediction of Radiated Emissions Using Near-Field Measurement, IEEE Tran. EMC, Vol. PP, No. 9, pp. 1-9, doi: 10.1109/TEMC.2011.2141998.

Weng, H., Beetner, D. G., DuBroff, R. E., \& Shi, J. (2005). Estimation of Current from Near-Field Measurement, in Proc. of IEEE Int. Symp. EMC, Chicago, IL, Vol. 1, pp. 222-227.

Wiles, M. (2003). An Overview of Automotive EMC Testing Facilities, In Proc. of Automotive EMC Conf. 2003, Milton Keynes, UK.

Winter, W., \& Herbrig, M. (2009). Time Domain Measurement in Automotive Applications, in Proc of IEEE Int. Symp. EMC, Austin, Texas (USA), pp. 109-115.

Yang, T., Bayram, Y., \& Volakis, J. L. (2010). Hybrid Analysis of Electromagnetic Interference Effects on Microwave Active Circuits Within Cavity Enclosures, IEEE Trans. EMC, Vol. 52, No. 3, pp. 745-748. 


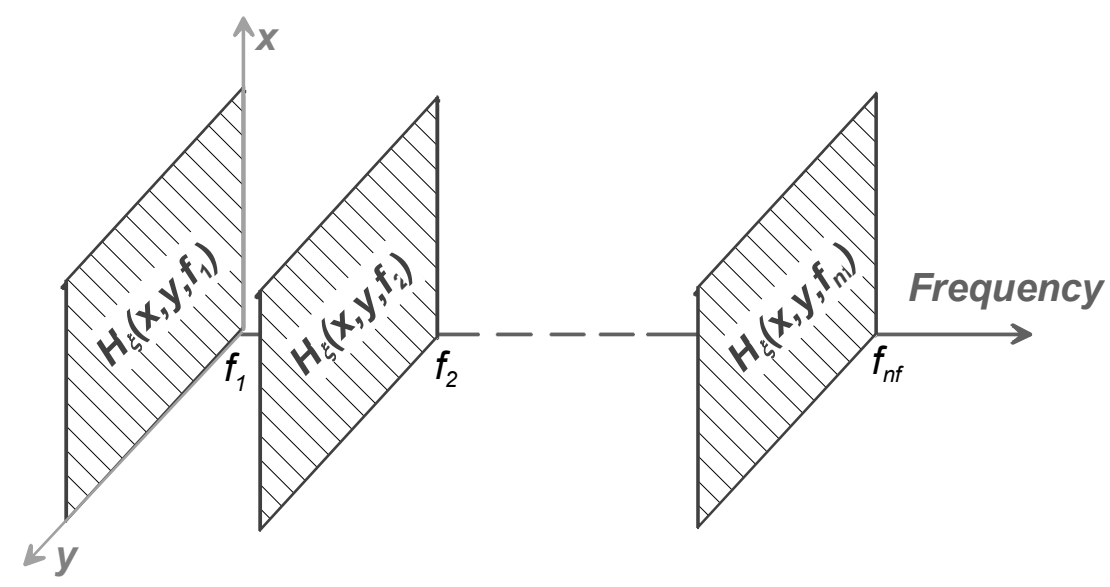

Figure 1. Representation of broadband frequency magnetic field maps from $f_{l}$ to $f_{n f}$

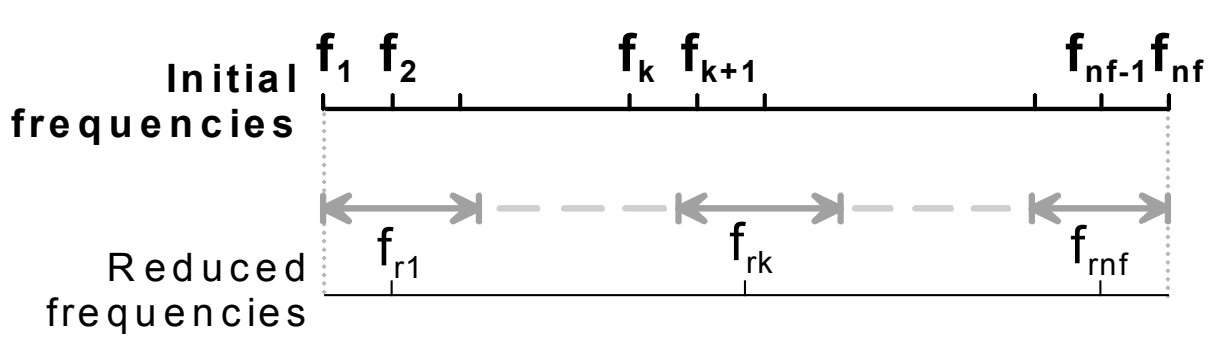

Figure 2. Illustration of the frequency number or broadband frequency maps reduction

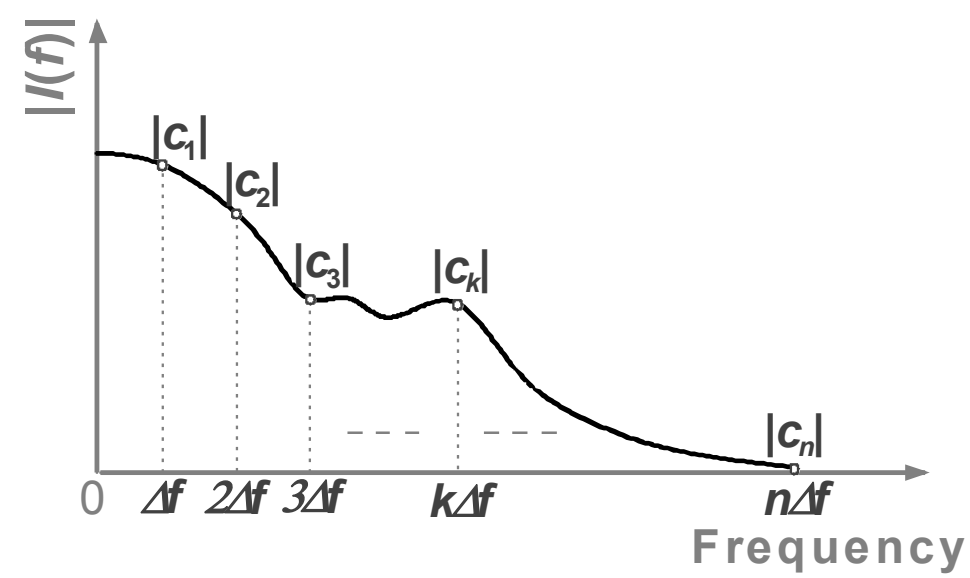

Figure 3. Representation of the frequency coefficients of the excitation signal considered

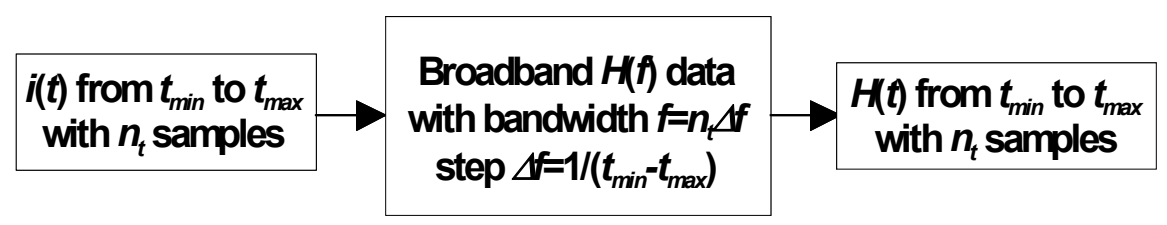

Figure 4. Illustration of the time-dependent NF calculation through the LTI convolution principle between the excitation source and the broadband magnetic field frequency data 


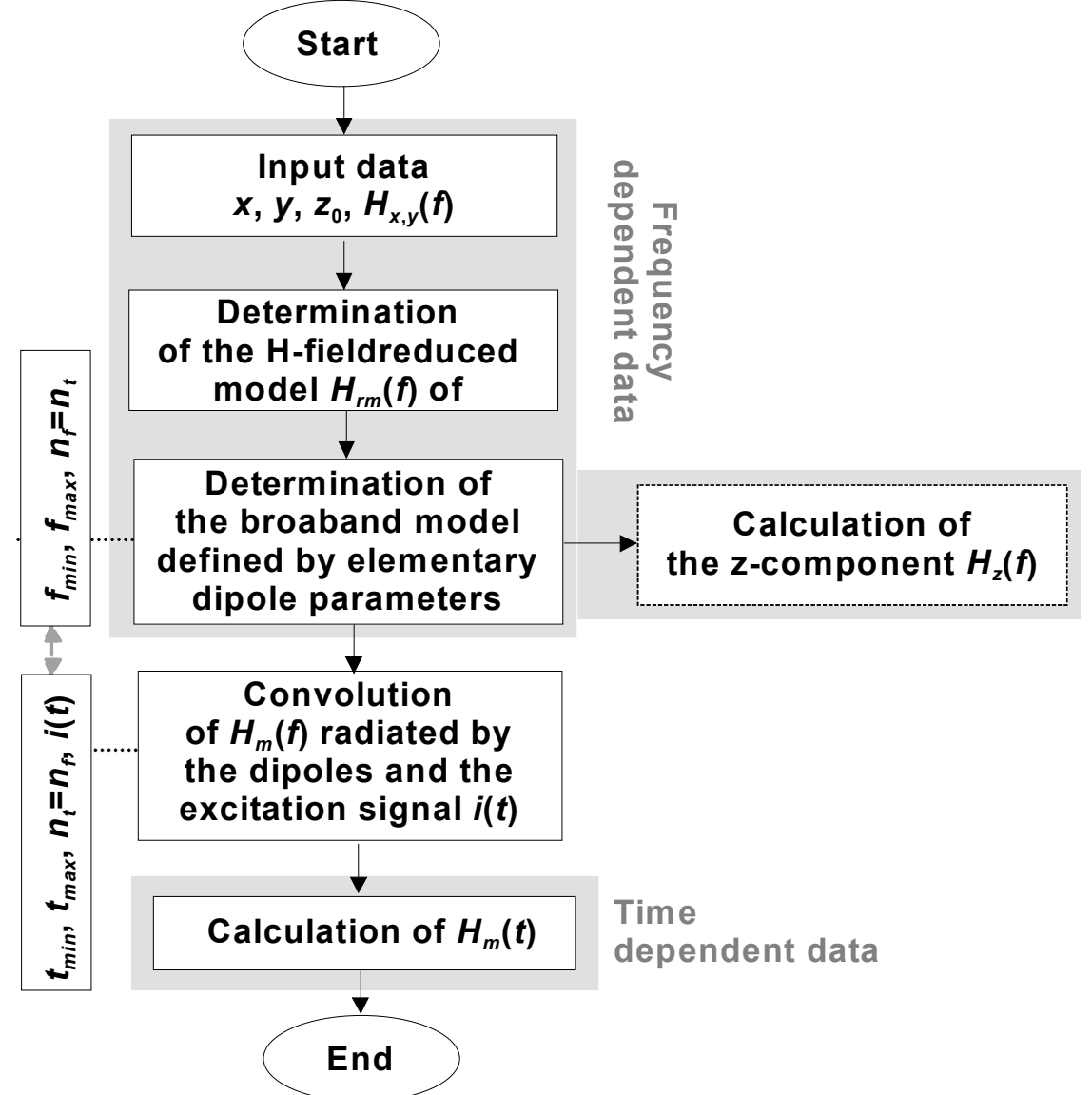

Figure 5. Work flow summarizing the time-frequency modeling method proposed
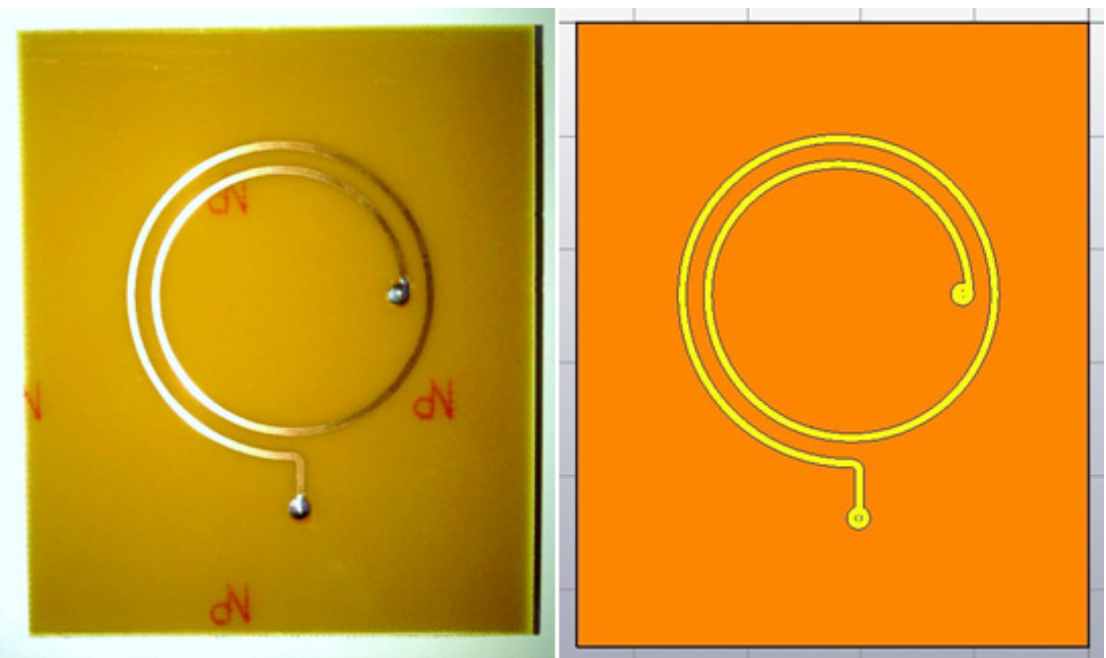

Figure 6. Top view of the under test microstrip device: photograph (in left) and 3D design with CST MWS (in right) 


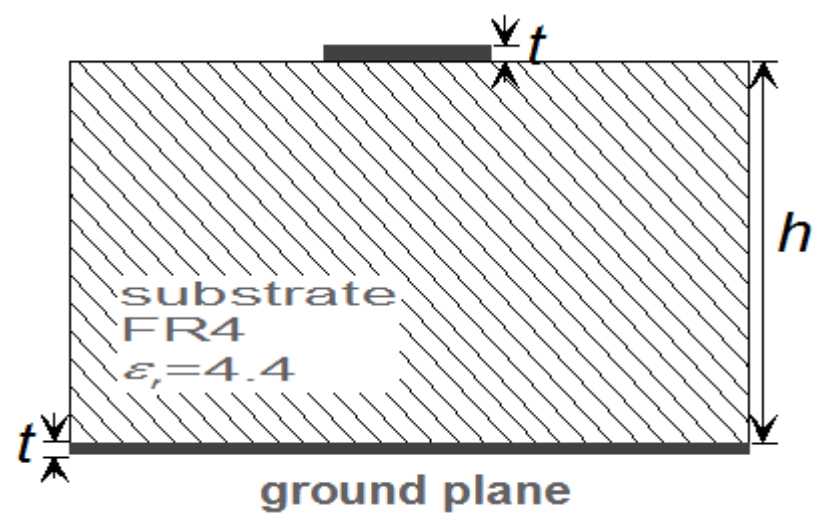

Figure 7. Cross-section cut of the under test microstrip device with metallization thickness $t=35 \mu \mathrm{m}$ and dielectric substrate height $h=1.6 \mathrm{~mm}$
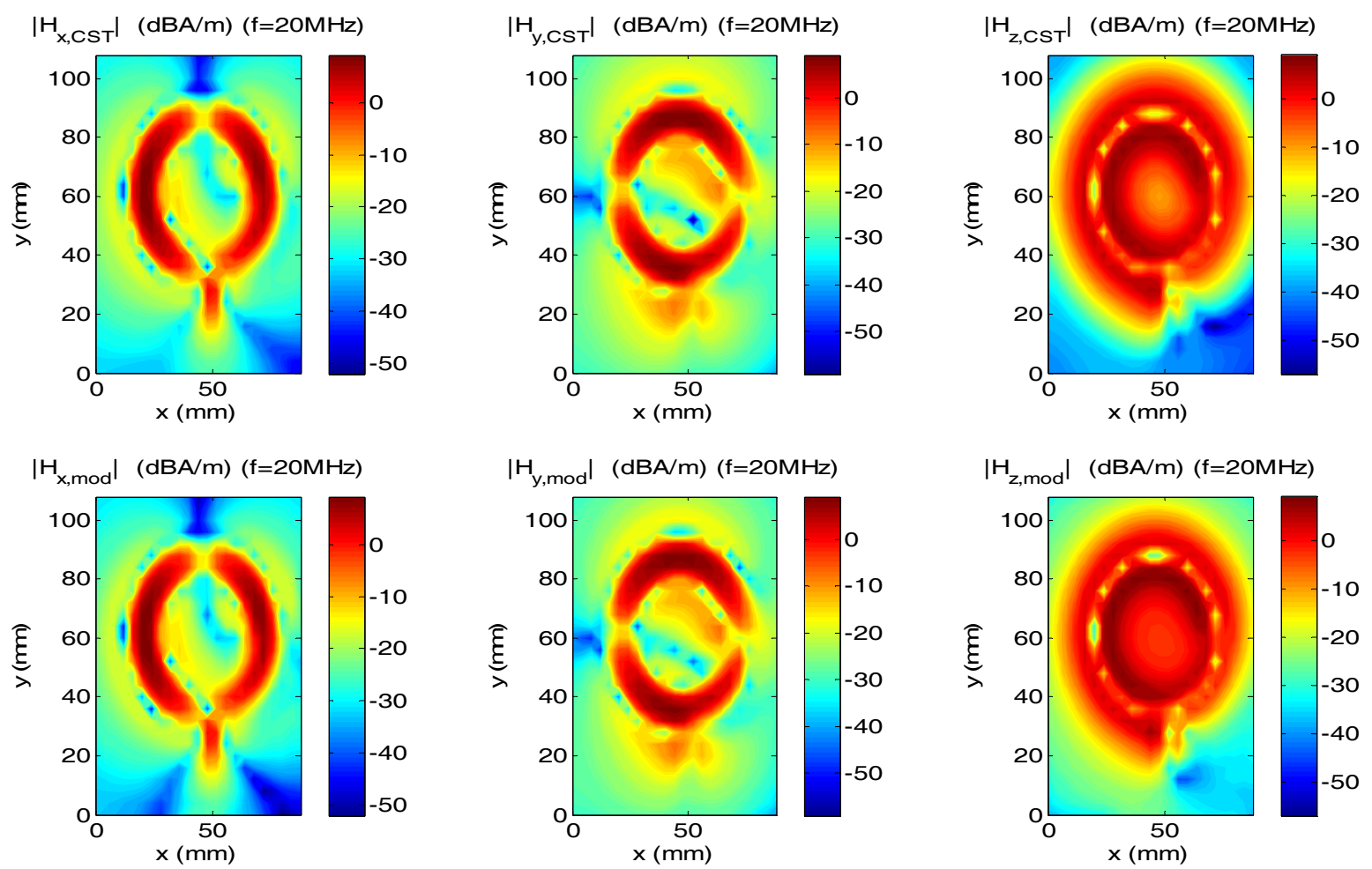

Figure 8(a). Magnetic field maps obtained by the simulation and the reduced broadband model for $f=20 \mathrm{MHz}$ 

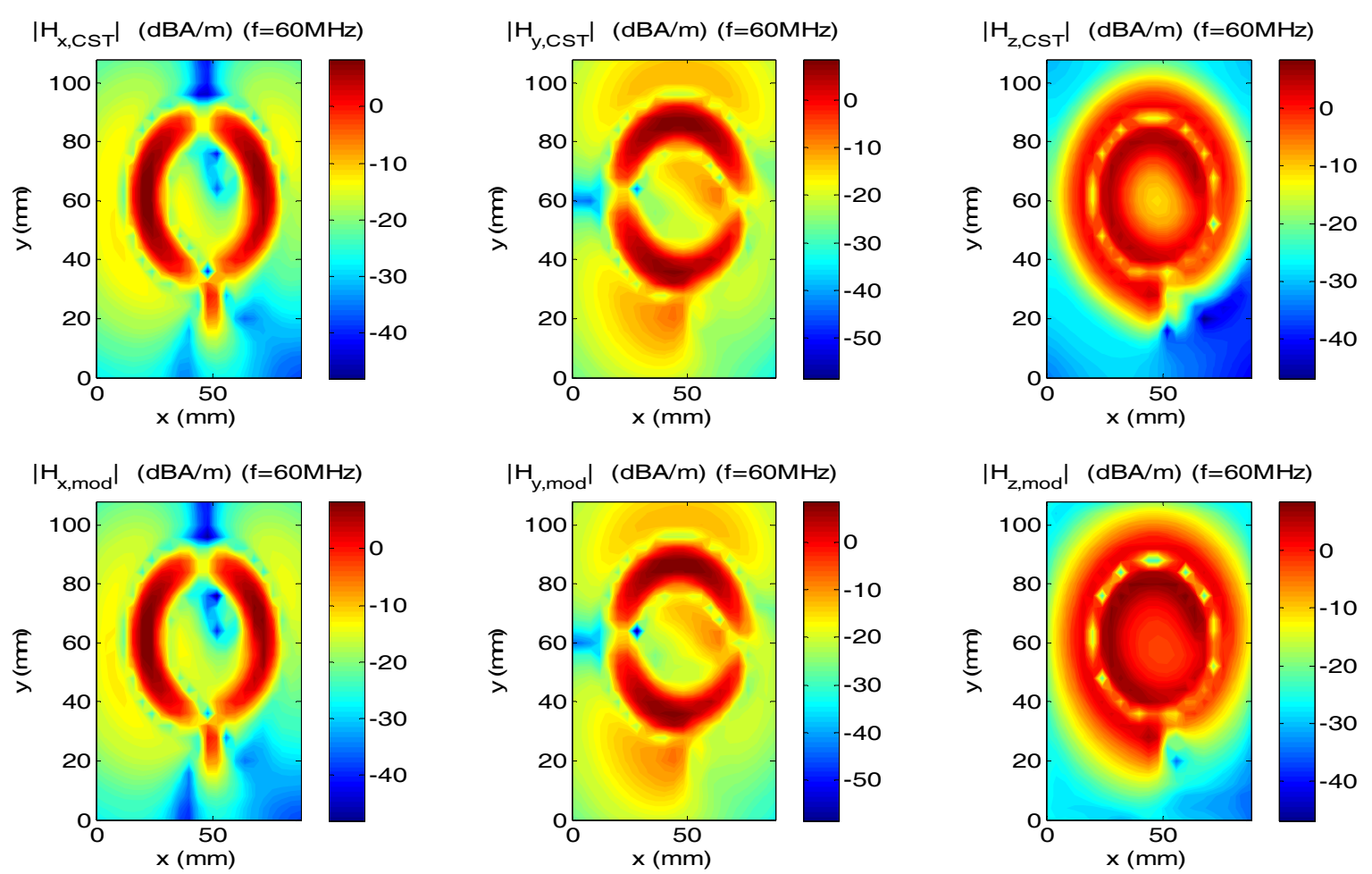

Figure 8 (b). Magnetic field maps obtained by the simulation and the reduced broadband model for $f=60 \mathrm{MHz}$
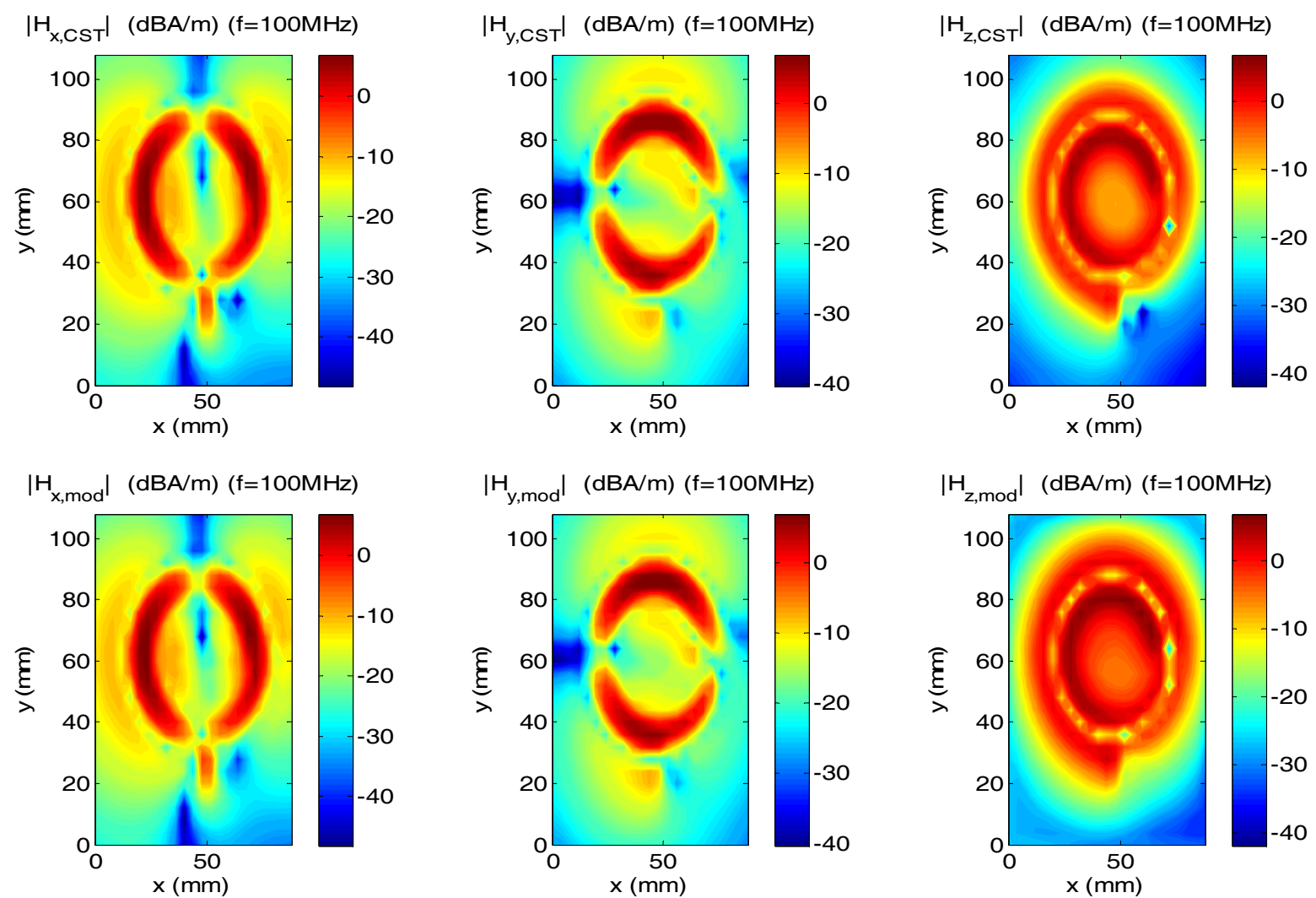

Figure $8(\mathrm{c})$. Magnetic field maps obtained by the simulation and the reduced broadband model for $f=100 \mathrm{MHz}$ 


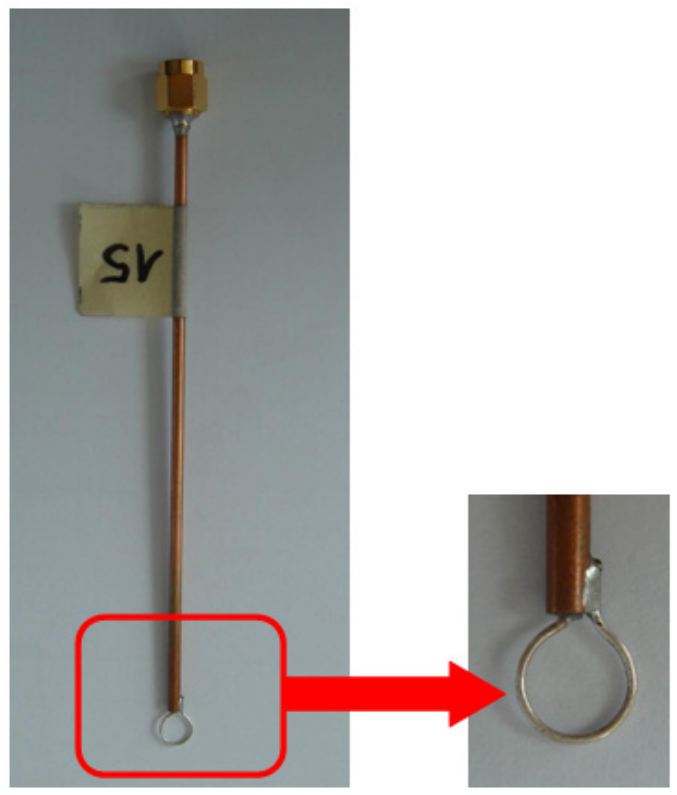

Figure 9. Photograph of the magnetic probe employed to measure the magnetic NF

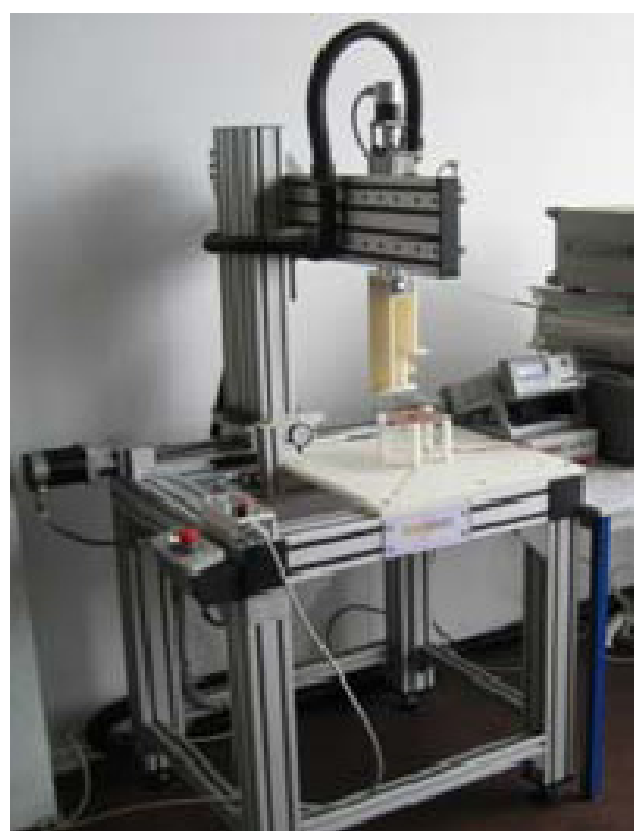

Figure 10. Photograph of the IRSEEM test bench used for the magnetic NF measurement 

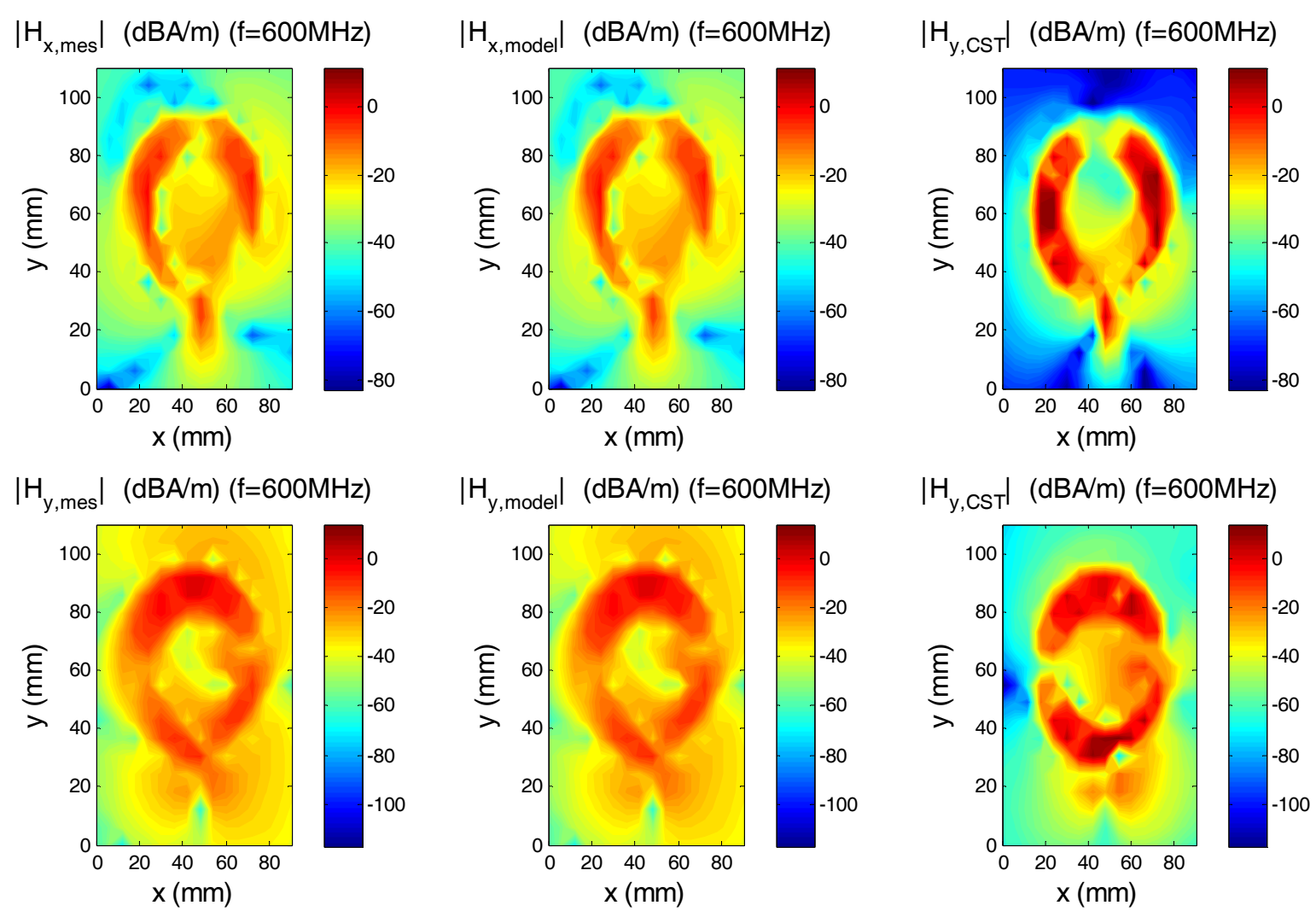

Figure 11(a). Comparison of $H_{x}$ and $H_{y}$ obtained from measurement, simulation and the broadband model proposed for $f=0.6 \mathrm{GHz}$
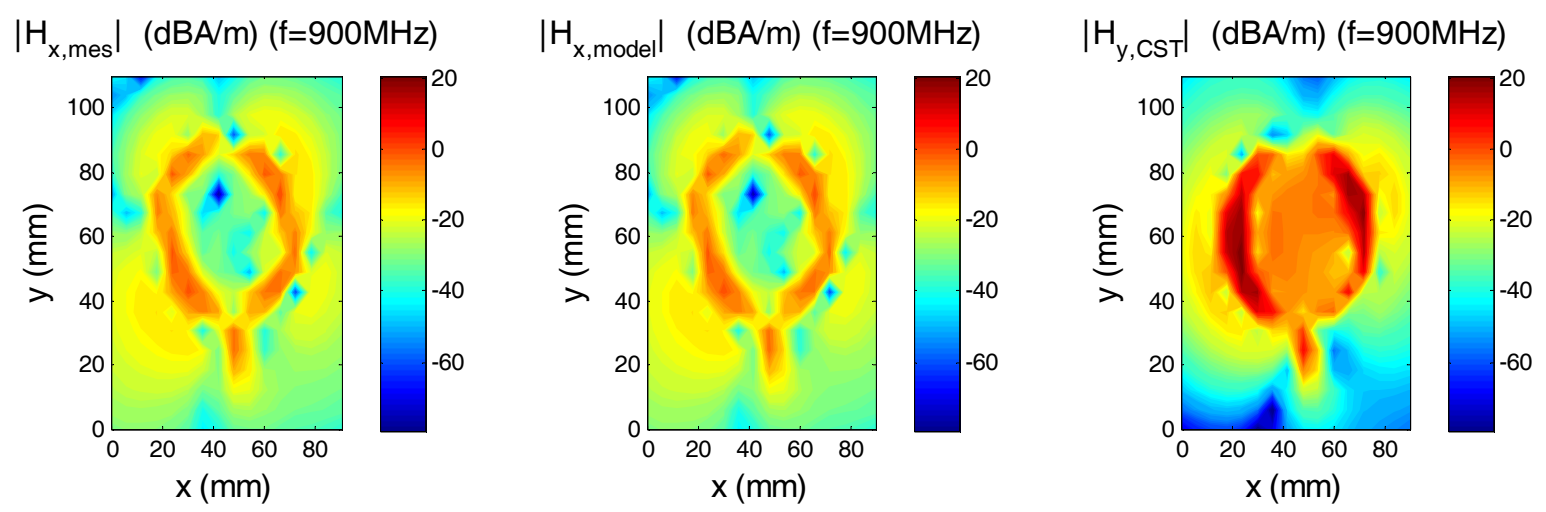

$\left|\mathrm{H}_{\mathrm{y}, \mathrm{mes}}\right|(\mathrm{dBA} / \mathrm{m})(\mathrm{f}=900 \mathrm{MHz})$

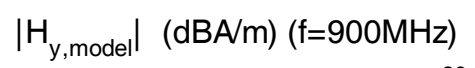

$\left|\mathrm{H}_{\mathrm{y}, \mathrm{CST}}\right|(\mathrm{dBA} / \mathrm{m})(\mathrm{f}=900 \mathrm{MHz})$
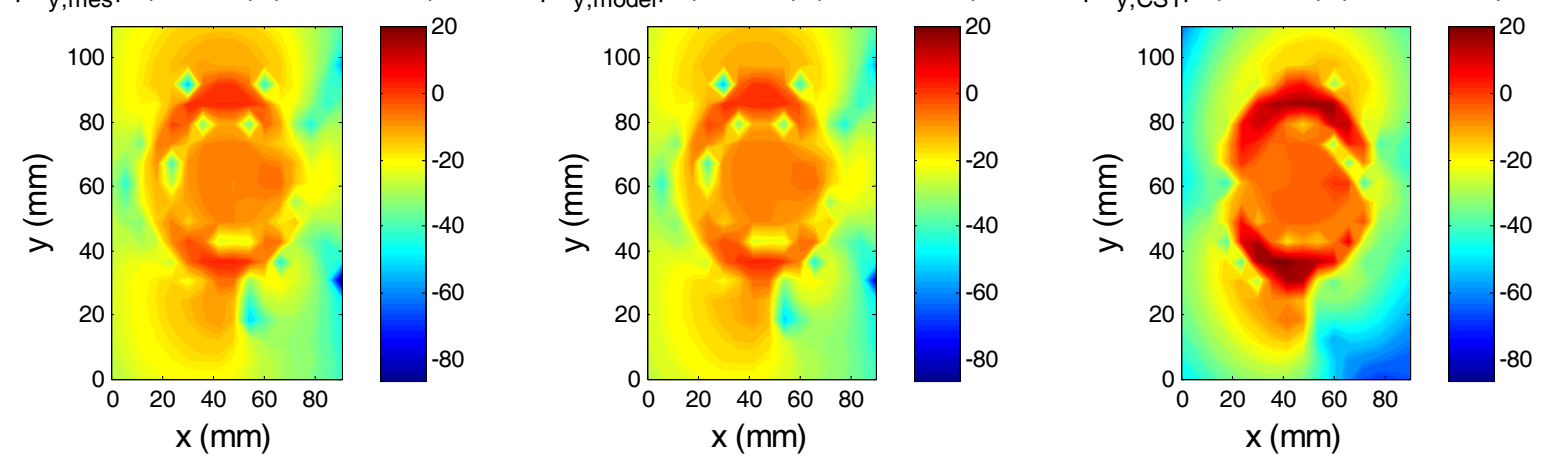

Figure 11(b). Comparison of $H_{x}$ and $H_{y}$ obtained from measurement, simulation and the broadband model proposed for $f=0.9 \mathrm{GHz}$ 

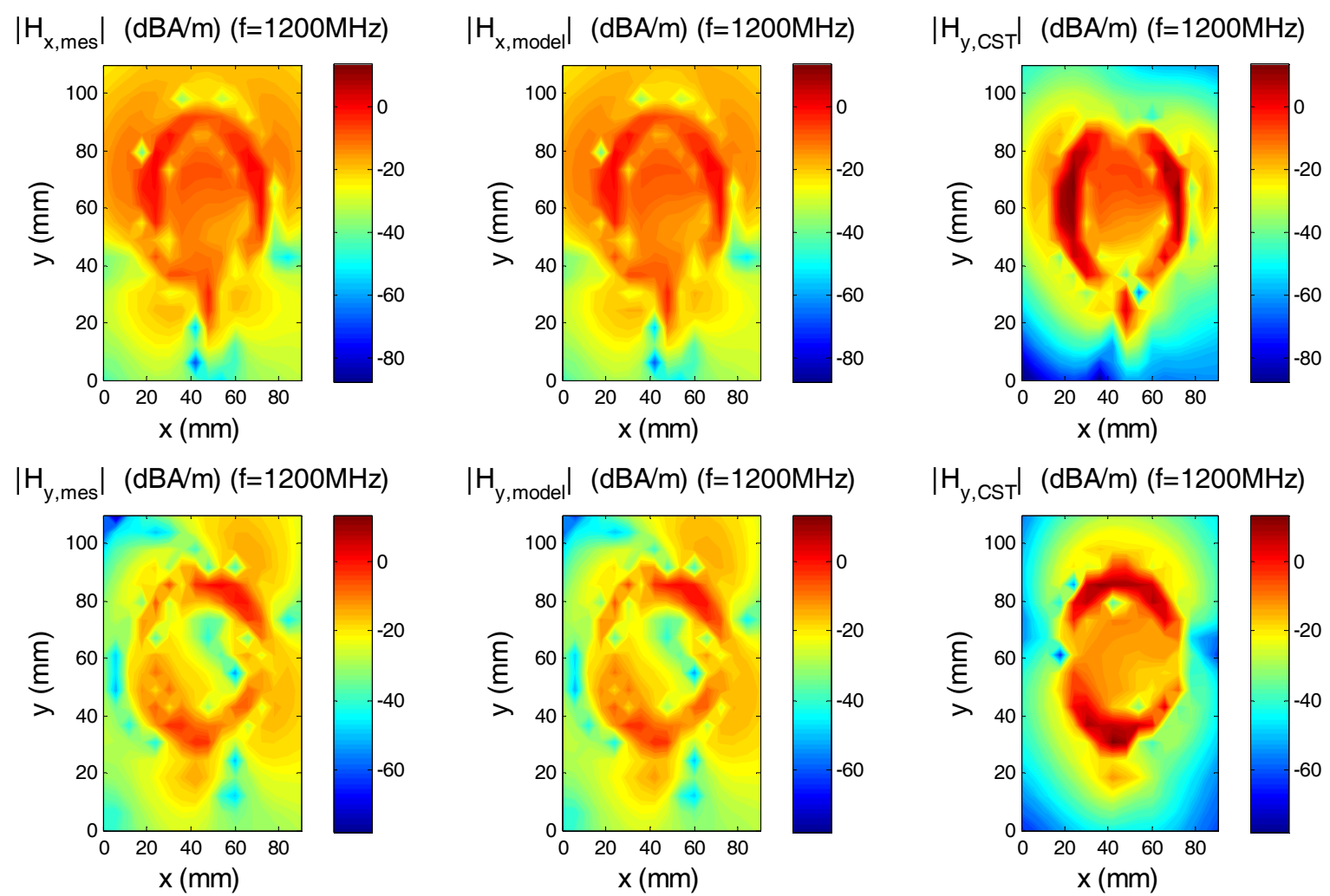

Figure 11(c). Comparison of $H_{x}$ and $H_{y}$ obtained from measurement, simulation and the broadband model proposed for $f=1.2 \mathrm{GHz}$
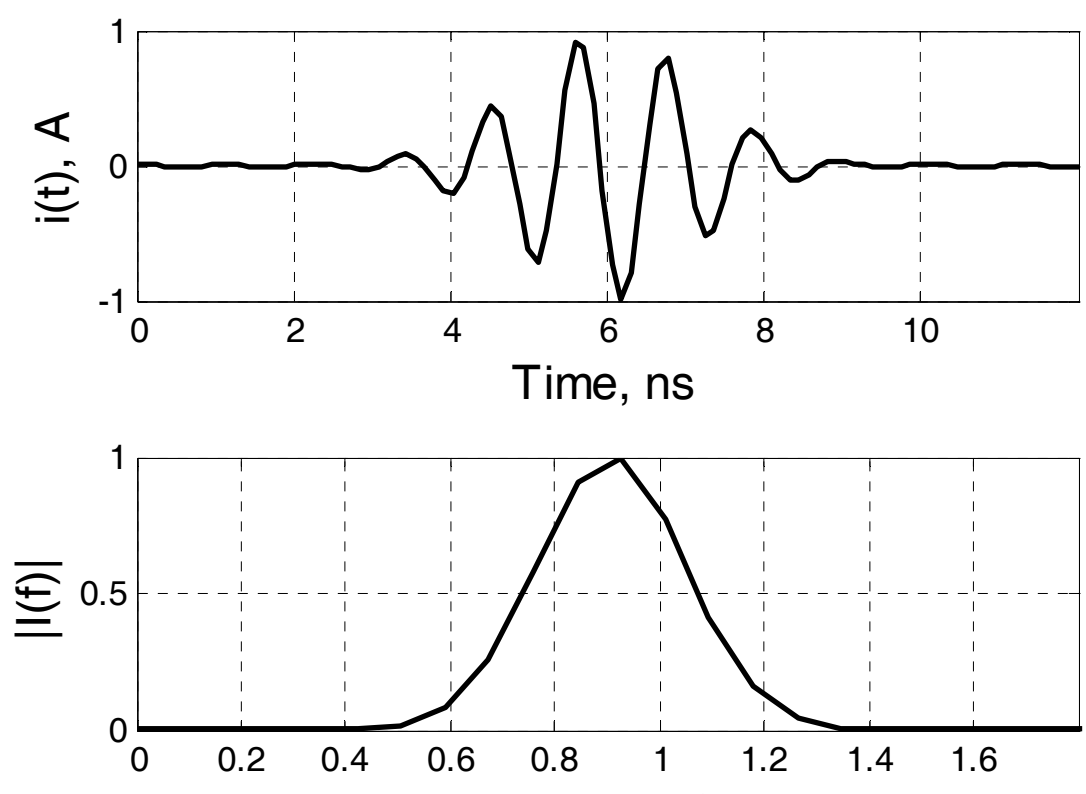

Frequency, $\mathrm{GHz}$

Figure 12. Transient excitation signal (in top) considered and its frequency spectrum (in bottom) 

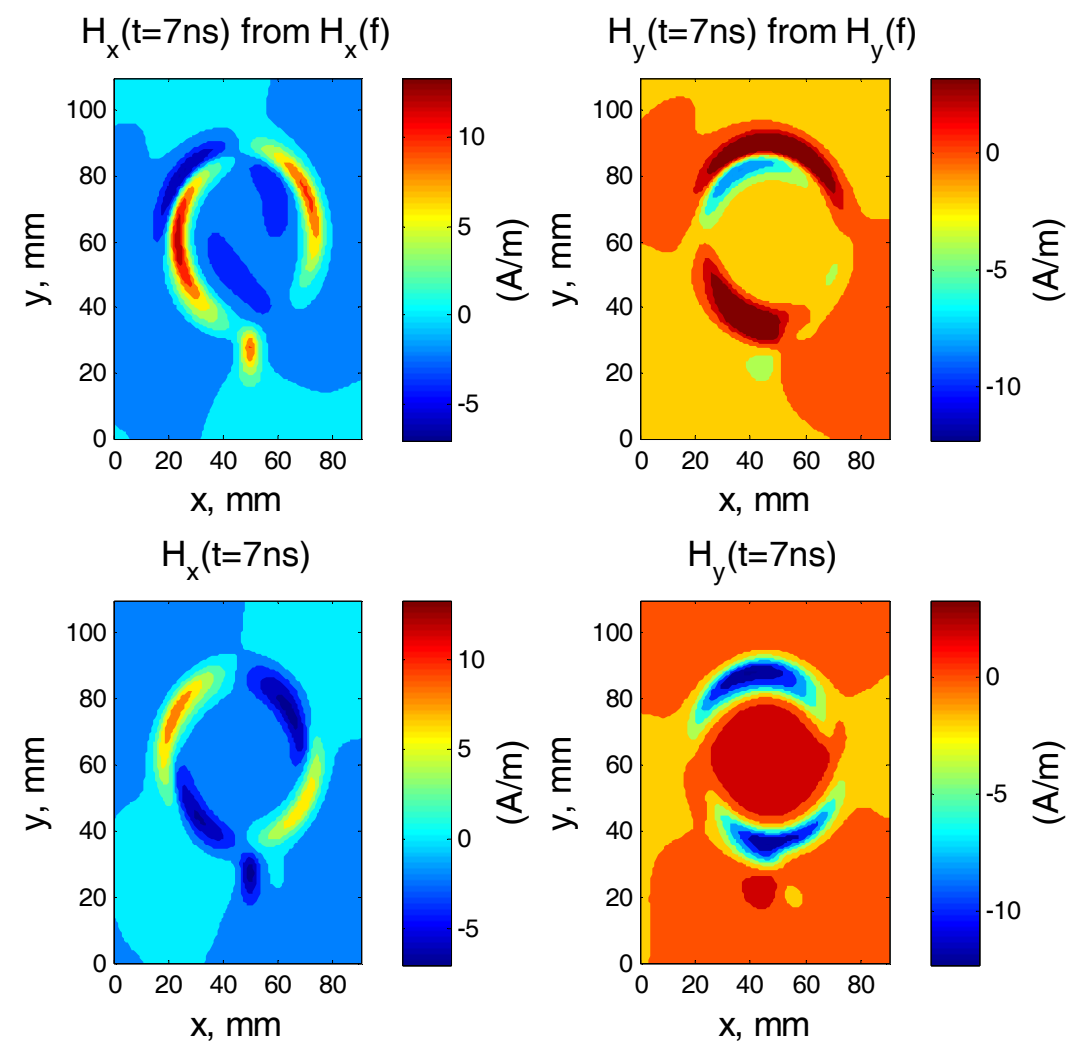

Figure 13(a). Comparison of time-domain results from the method proposed and from CST maps of $H_{x}$ and $H_{y}$ computed at the instant time $t=7 \mathrm{~ns}$

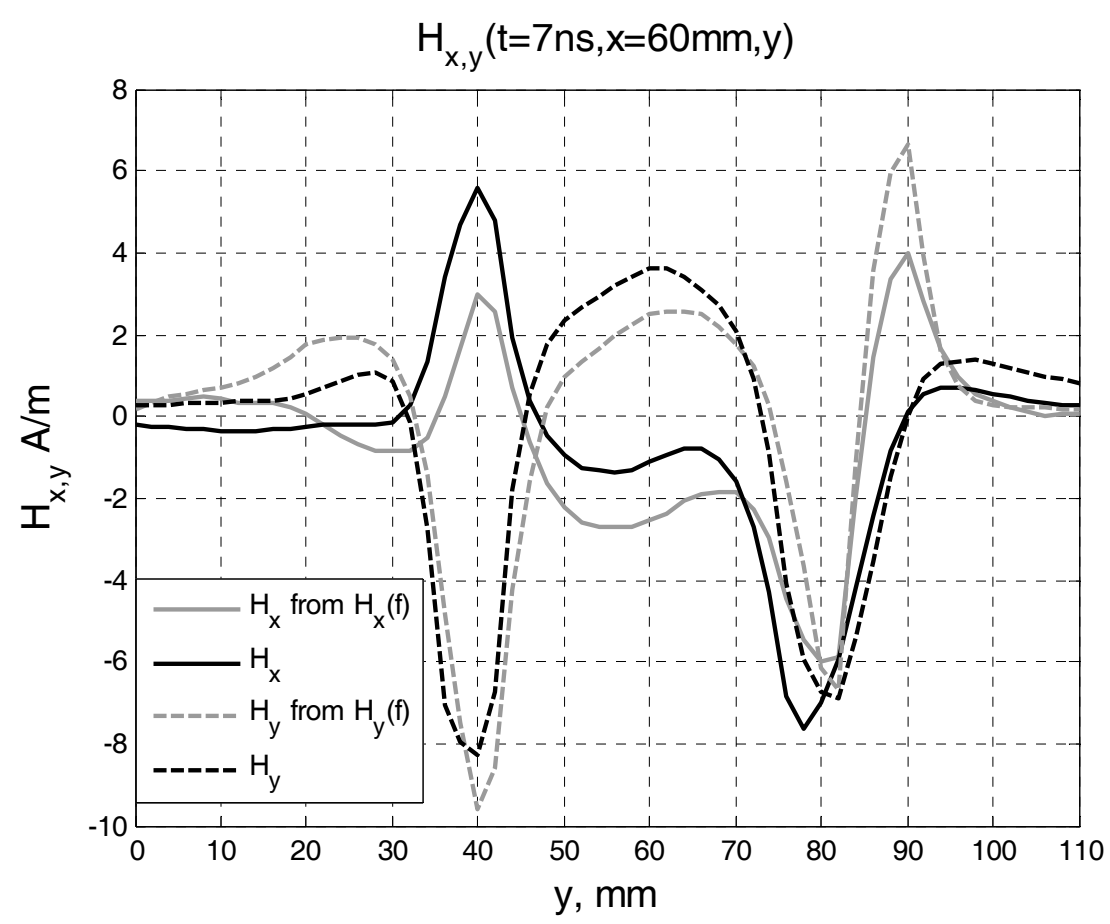

Figure 13(b). Comparison of time-domain results from the method proposed and from CST profiles of $H_{x}$ and $H_{y}$ computed at the instant time $t=7 \mathrm{~ns}$ 